\title{
Correction to: Microstructural Evolution and Ductile- to-Brittle Transition in a Low-Carbon MnCrMoNiCu Heavy Plate Steel
}

\author{
DONGSHENG LIU, MI LUO, BINGGUI CHENG, RUI CAO, and JIANHONG CHEN
}

https://doi.org/10.1007/s11661-018-4856-0

(c) The Minerals, Metals \& Materials Society and ASM International 2018

\section{Correction to: Metallurgical and Materials Transactions A https://doi.org/10.1007/s11661-018-4823-9}

IN the original article the following errors occurred: In the last sentence of the first paragraph in the Experimental Procedures section, $11 \mathrm{~mm} \times 1 \mathrm{~mm} \times 75$ $\mathrm{mm}$ is incorrect. The correction dimensions are $11 \mathrm{~mm} \times 11 \mathrm{~mm} \times 75 \mathrm{~mm}$.

In the second sentence of the fifth paragraph in the Experimental Procedures section, the corrected text is as follows: the impact energy was measured at room temperature, $253 \mathrm{~K}, 213 \mathrm{~K}, 188 \mathrm{~K}, 168 \mathrm{~K}$, or $77 \mathrm{~K}$ $\left(\mathrm{RT}, \quad-20{ }^{\circ} \mathrm{C},-60{ }^{\circ} \mathrm{C},-85{ }^{\circ} \mathrm{C},-105^{\circ} \mathrm{C}\right.$, or
- $196{ }^{\circ} \mathrm{C}$ ) by employing a $450-\mathrm{J}$ instrumented pendulum impact tester with a tup striker of radius $2 \mathrm{~mm}$.

In the Results section, section $\mathrm{C}$, first paragraph, second to last sentence, the correct Table citation is Table II.

In the fifth sentence of the second paragraph in section $\mathrm{C}$ of the Results section, the austenitizing temperature in Celsius is missing. The correct temperature is $1623 \mathrm{~K}\left(1350{ }^{\circ} \mathrm{C}\right)$.

In section $G$ of the Results section, last paragraph, second to last sentence, " $\gamma_{\mathrm{f}}$ " is an error. The correct symbol is $\sigma_{\mathrm{f}}$ which stands for the local cleavage fracture stress.

DONGSHENG LIU, MI LUO, and BINGGUI CHENG are with the Institute of Research of Iron and Steel, Jiangsu Shagang Group Co., Ltd, Jinfeng Town, Zhangiiagang, Jiangsu Province 215625, P.R. China. Contact e-mail: dongshengl@hotmail.com RUI CAO and JIANHONG CHEN are with the State Key Laboratory of Gansu Advanced Processing and Recycling of Non-ferrous Metallic Metals and Key Laboratory of Non-ferrous Metal Alloys of the Ministry of Education, Lanzhou University of Technology, Lanzhou 730050, P.R. China.

The original article can be found online at https://doi.org/10.1007/ s11661-018-4823-9.

Article published online August 1, 2018 